\title{
Correction to: Lloyd R. Snyder: An Appreciation 1931-2018
}

\author{
Imre Molnár ${ }^{1}$
}

Published online: 8 February 2019

๑) Springer-Verlag GmbH Germany, part of Springer Nature 2019

\section{Correction to: Chromatographia https://doi.org/10.1007/s10337-018-3657-3}

The publisher apologizes for the incomplete legend of Fig. 1 in the original version of this article. The correct information of Fig. 1 is given below:

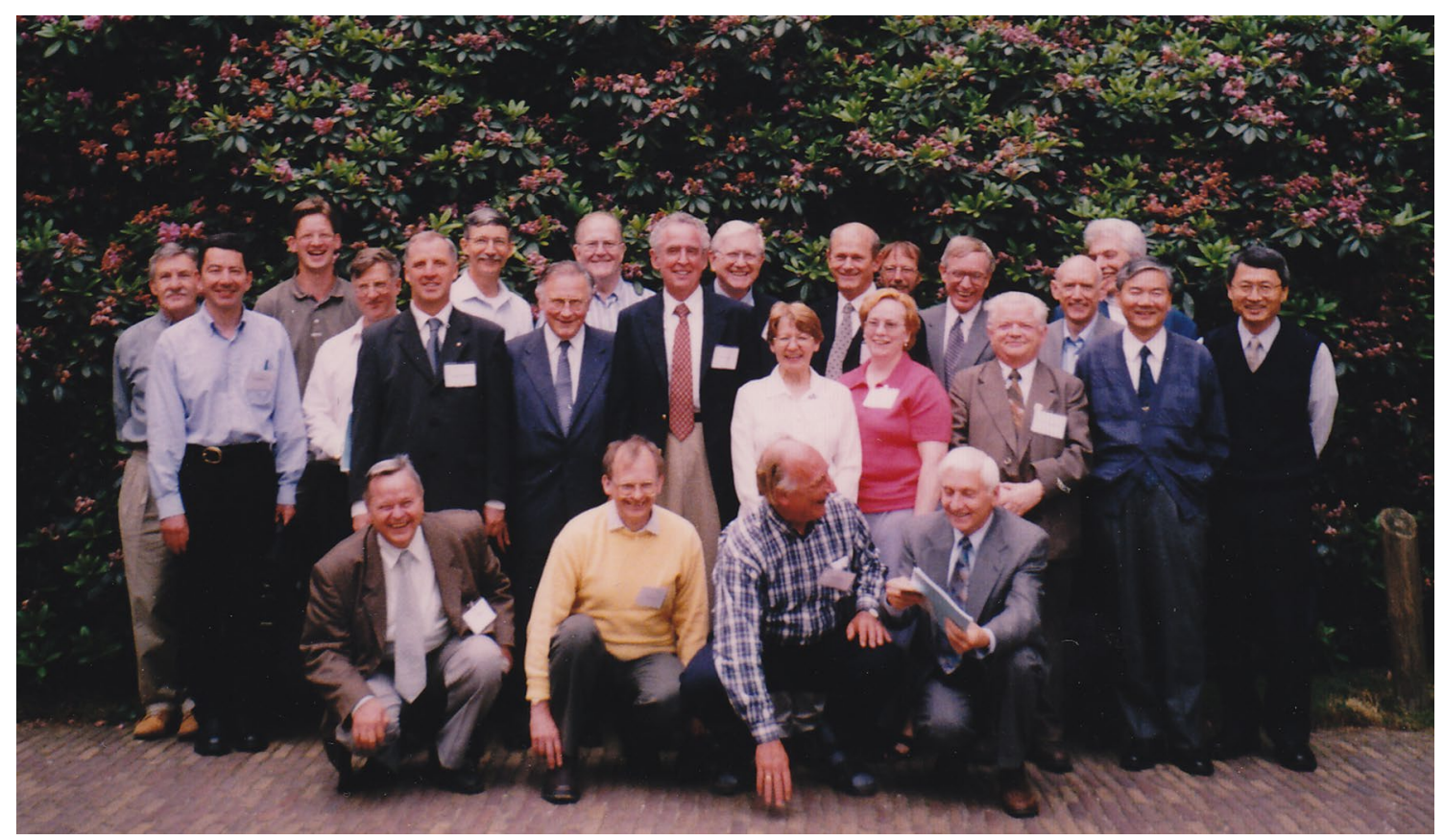

Fig. 1 A group photo with of Lloyd with his friends and colleagues in 2001 at his 70th birthday. The event was organized by Elsevier in Ellecom in the Netherland. Top row: Peter Schoenmakers, John Dolan, Peter Carr, Jack Kirkland, Imre Molnár, Klaas Bij, John Dorsey, Roger Giese, Rob Marx, Shigeru Terabe, Nobuo Tanaka;

The original article can be found online at https://doi.org/10.1007/ s10337-018-3657-3.

Imre Molnár

imre.molnar@molnar-institute.com

1 Molnár-Institute for Applied Chromatography,

Schneegloeckchenstrasse 47, 10407 Berlin, Germany middle row: Erich Heftmann, David McCalley, Gyula Vigh, Roman Kaliszan, Csaba Horváth, Lloyd Snyder, Sandra Poole, Sarah Rutan, Edward Soczewinski; bottom row: Pavel Jandera, Colin Poole, Hans Poppe, Vadim Davankov. (George Guiochon is missing)

Publisher's Note Springer Nature remains neutral with regard to jurisdictional claims in published maps and institutional affiliations. 